\title{
Revitalização de espaços culturais/pedagógicos
}

\author{
Recebido em 29.04.2015. Aprovado em 05.05. 2015
}

Avaliado pelo sistema double blind review

\author{
Maria Bellezoni Marinho \\ maria.bellezonimarinho@gmail.com \\ Escola Estadual Professora Ana Pinto Duarte Paes - Jundiaí - SP - Brasil.
}

\section{Resumo}

A Escola Estadual Professora Ana Pinto Duarte Paes trabalha no modelo Ensino Integral nos segmentos: Ensino Fundamental Ciclo II - Anos Finais e Ensino Médio; que prima pela excelência acadêmica no apoio integral aos projetos de vida dos alunos.

Durante as análises para a elaboração do plano de ação da escola, que determina os objetivos e as metas para efetivar uma aprendizagem com excelência acadêmica, detectou-se a necessidade de privilegiar adequações de espaços para oportunizarem a transformação das dinâmicas e das metodologias diferenciadas de sala de aula, abrangendo a diversidade cognitiva e seduzindo os alunos a envolverem-se em seus próprios processos de aprendizagem, tendo como principais objetivos:

Associar o sentimento de liberdade da juventude com o ambiente pedagógico;

Desenvolvimento de ações protagonistas.

A proposta é revitalizar espaços para serem utilizados nas atividades de cunho pedagógico que serão alinhavadas pelos professores das disciplinas do currículo e da parte diversificada, através de projetos que tenham como foco central o envolvimento dos alunos do Ensino Médio.

O PROEMI (programa ensino médio inovador - mec/fnde) está sendo um facilitador para a realização deste projeto, pois suprirá a necessidade das verbas para sua execução.

Para que este projeto tenha sucesso inovador todo o processo será registrado e divulgado nos murais da escola através de cartazes com fotos de todas as fases/etapas da revitalização, publicação no Blog da escola e em reuniões de pais.

O principal resultado que a escola almeja é o aumento do índice do IDESP, sendo o foco principal a melhoria do indicador de fluxo.

O valor estimado para utilização na revitalização da estrutura física é de $R \$ 11.120,00$, porém após seu término haverá as despesas administrativas e de pessoal prevista em $\mathrm{R} \$ 68.513,76 /$ ano; investimentos estes, que visarão um melhor aproveitamento dos espaços culturais/pedagógicos no interior da escola além de oportunizar momentos diferenciados de convivência e aprendizado.

Palavras-chaves: Educação. Revitalização de espaços pedagógicos. Plano de empreendimento. 


\section{Contexto da escola}

A Escola Estadual Professora Ana Pinto Duarte Paes foi fundada há 51 anos, com destaque para o ensino médio. De 2006 até o ano passado seguia o modelo ETI - Escola de Tempo Integral para o ensino fundamental e sistema regular com o ensino médio. Em 2013 após pesquisas e reuniões com a equipe e comunidade escolar optou-se por aderir ao PROGRAMA DE ENSINO INTEGRAL para 0 ano de 2014 nos dois segmentos.

\section{Identificação da unidade escolar:}

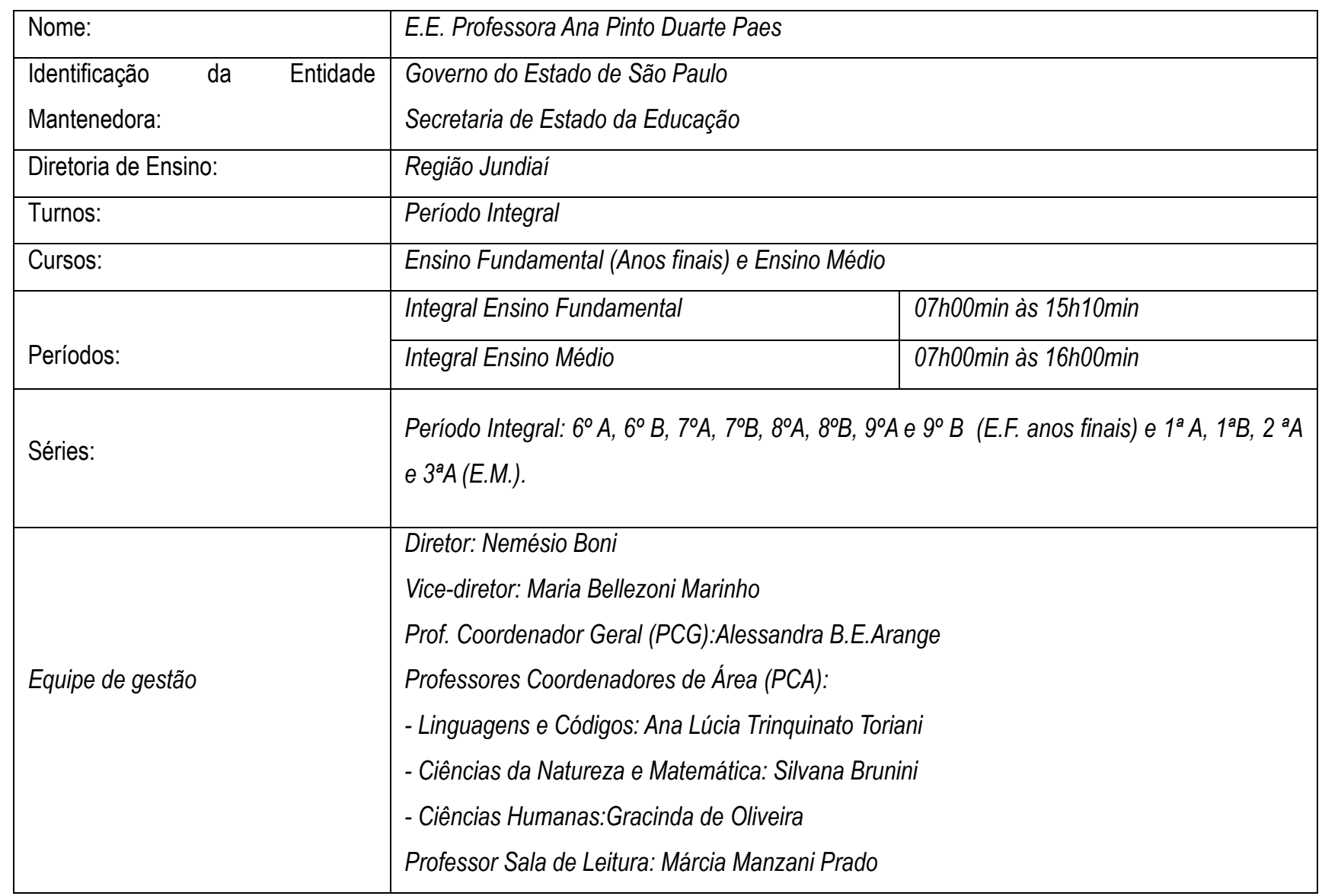




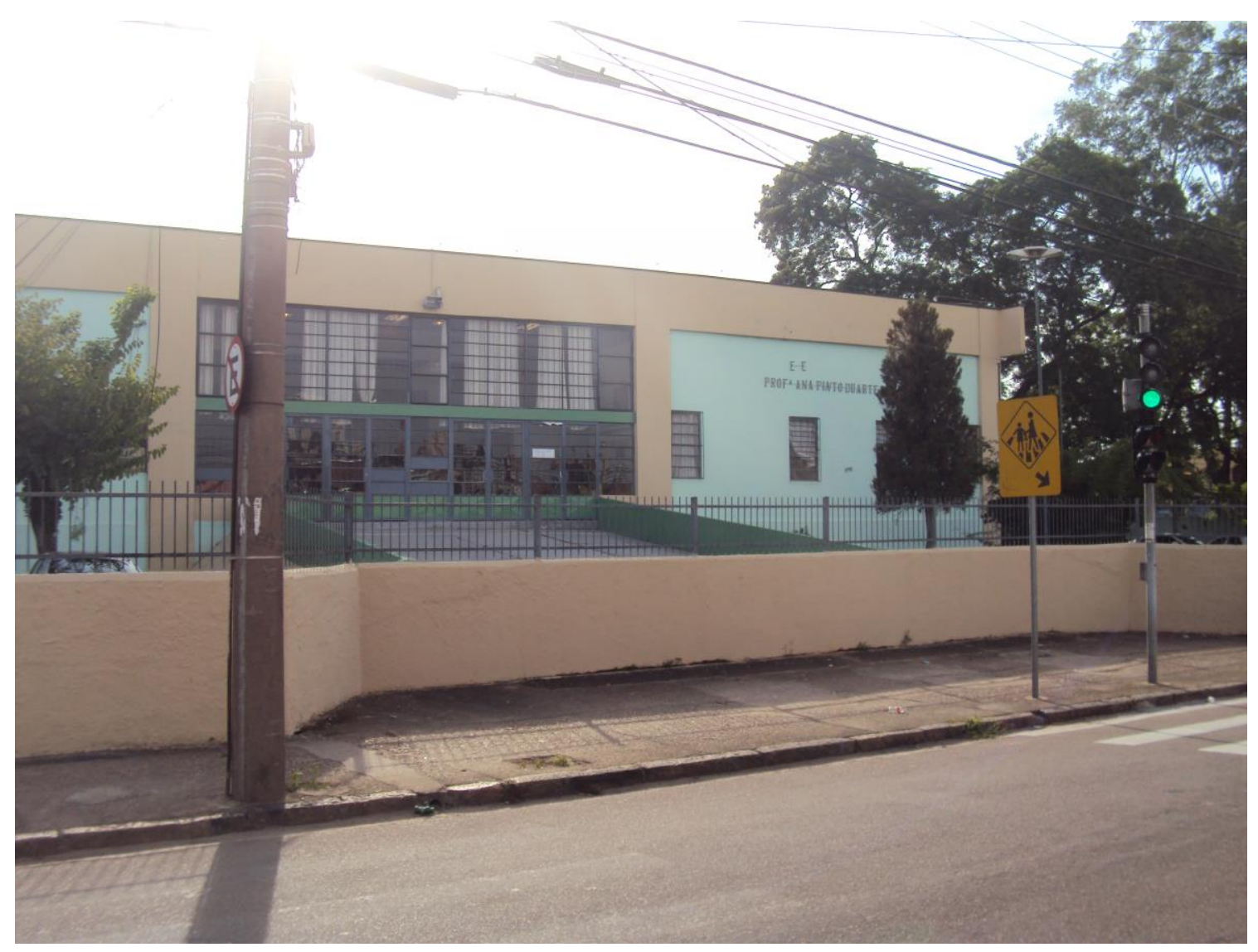

\section{Missão:}

Ser um núcleo formador de jovens primando pela excelência acadêmica; no apoio integral aos seus projetos de vida; seu aprimoramento como pessoa humana; formação ética; o desenvolvimento da autonomia intelectual e do pensamento crítico.

No modelo pedagógico, quatro princípios educativos fundamentais orientam a constituição das metodologias, sempre como referência a busca pela formação de um jovem autônomo, solidário e competente. Os quatro princípios são: A Educação Interdimensional, A Pedagogia da Presença, Os Quatro Pilares da Educação para o Século XXI e o Protagonismo Juvenil.

\section{Visão:}

Até 2030 alcançar o IDESP (Índice de Desenvolvimento do Estado de São Paulo) de 6.0 para que a Secretaria de Educação do Estado de São Paulo (SEE) seja reconhecida internacionalmente como uma rede de ensino integral pública de excelência posicionada entre as 25 primeiras do mundo.

O prédio escolar está situado no bairro da Ponte de São João, muito próximo à região central da cidade, este é um fator determinante para a composição do nosso público estudantil. $\mathrm{O}$ bairro é considerado um "bairro velho", por isto o alunado é formado por jovens de diversos bairros, alguns próximos, outros nem tanto e até mesmo de cidades vizinhas.

O corpo docente é constituído por 20 professores, 1 professora da Sala de Leitura, 1 residente educacional e 3 gestores.

Todos os profissionais que trabalham nesta unidade escolar inscreveram-se no processo seletivo e submeteram-se a entrevistas na qual houve também a confirmação de títulos para análise de perfil. Após classificação aderiram ao programa; nesta seleção $40 \%$ dos docentes são professores que já atuavam na escola e $60 \%$ advindos de outras unidades. 
Para 0 ano de 2014 a meta estabelecida pela SEE rege um aumento de $6 \%$ sobre o resultado do IDESP de 2013, ou seja, precisamos cumprir a meta de 2,94 para o ensino fundamental e 2,25 para o ensino médio.

\section{Perfil dos alunos e professores:}

$\mathrm{Na}$ escola Estadual Professora Ana Pinto Duarte Paes os profissionais que atuam têm uma trajetória profissional acadêmica entre 4 e 25 anos de docência, todos com formação de nível superior, dos quais 75\% são pós-graduados, perfazendo um total de 21 professores, sendo um deles uma professora readaptada que atua na Sala de Leitura.

Hoje, a escola atende ao Ensino Fundamental anos finais com um total de 281 alunos e, 70 alunos no Ensino Médio ambos em período integral, nas seguintes turmas:

\begin{tabular}{|c|c|}
\hline $\begin{array}{c}\text { ANO DE ESCOLARIDADE } \\
\text { SEGMENTO }\end{array}$ & $\mathbf{N}^{\circ}$ DE TURMAS \\
\hline $6^{\circ} \mathrm{ano} /$ E.F. & 2 \\
\hline $7^{0} \mathrm{ano} /$ E.F. & 2 \\
\hline $8^{\circ} \mathrm{ano} /$ E.F. & 2 \\
\hline $9^{\circ} \mathrm{ano} /$ E.F. & 2 \\
\hline $1^{\circ}$ ano / E.M. & 2 \\
\hline $2^{\circ}$ ano / E.M. & 1 \\
\hline $3^{\circ}$ ano / E.M. & 1 \\
\hline TOTAL DE TURMAS & 12 \\
\hline
\end{tabular}

\section{Histórico}

A história do bairro Ponte São João remonta ao final do século XIX e está relacionada à presença de imigrantes italianos na cidade. Durante décadas, o bairro que hoje abriga grandes indústrias e um intenso comércio, foi ocupado apenas por poucas casas; suas ruas eram iluminadas por lampiões. Conta a tradição oral que, no passado, a ponte sobre o Rio Jundiaí era feita de madeira e as crianças tinham no rio um de seus pontos de lazer.

O bairro da Ponte São João está localizado na Região Leste do Município. Na década de 1950, a construção do Viaduto São João Batista, antiga reivindicação dos moradores e comerciantes do local, promoveu um grande crescimento na região e facilitou sobremaneira os contatos com o centro da cidade.

De acordo com o censo IBGE 2000 a densidade demográfica do bairro apresentava a seguinte estatística com relação a idade dos moradores:

\section{0 a 9 anos de $9,58 \%$}

10 a 19 anos $15,33 \%$ 
20 a 39 anos $29,13 \%$

40 ou mais $45,96 \%$

A Instituição de Ensino foi criada pela lei estadual nº 6180 de 14/07/1961, iniciou suas atividades em 14 de abril de 1963 no então Ginásio Estadual da Ponte São João, localizado na Rua Santo Antonio, $n^{0} 145$. Seu primeiro diretor foi o Profo Gustavo Leopoldo Maryssael de Campos. Em 1964, transferia suas instalações para Rua Dino, 151 no mesmo bairro, já contando com sua diretora efetiva Profa Norma Pires Gavião de Almeida. Contava nessa ocasião com 500 alunos distribuídos por todas as séries de $1^{\circ}$ grau. Em 27 de outubro de 1965, decreto 45.438 alterou sua denominação para Ginásio Estadual "Profa Ana Pinto Duarte Paes", como homenagem à imagem da educadora jundiaiense.

Em 1970 recebeu o curso de $2^{\circ}$ grau, passando a denominar-se Colégio Estadual Profa Ana Pinto Duarte Paes para, em 1973, receber do Fundo Estadual de Construções Escolares, seu prédio próprio e definitivo, localizado na Rua Carlos Gomes nº 770.

\section{Identificação do problema ou da oportunidade}

Para identificarmos o problema ou a oportunidade de aprimorar os índices de desempenho dos alunos, analisamos os resultados do IDESP 2012 e2013.

No ano de 2012 o resultado do Saresp (Sistema de Avaliação do Rendimento do Estado de São Paulo) foi insatisfatório, houve um decréscimo de $22,5 \%$ na meta estabelecida pela SEE no ensino fundamental e, 12\% no ensino médio, sendo em Língua Portuguesa o resultado mais estremecido e responsável por colocar a escola em situação de "prioritária".

No ano de 2013 ocorreu à redução de $0,10 \%$ de alunos no nível abaixo do básico na disciplina de Língua Portuguesa no $9^{\circ}$ ano, assim deixamos a denominação de "prioritária" e passamos a ser uma escola denominada "emergente". Quanto ao resultado do IDESP superamos a meta no ensino fundamental em $120 \%$ e a do ensino médio em $45 \%$ modificado para 60,45 considerando o índice de nível socioeconômico dos alunos. 0 índice do ensino médio foi comprometido pelo indicador de fluxo $(0,82)$, embora este tenha melhorado $22 \%$ em relação ao ano anterior.

0 indicador de fluxo reflete a realidade da escola, problema esse que, apesar de sua evolução, está caminhando de forma morosa. Para esta problemática estamos dialogando com toda a equipe escolar e verificando possíveis soluções, sendo uma elas a adequação dos espaços para atrair o aluno para a escola, de forma que se sinta num ambiente cultural diferenciado, prazeroso, onde possam participar de aulas diversificadas e significativas, favorecendo a formação de um jovem protagonista, solidário, autônomo e competente.

A defasagem dos alunos deve-se a sua frequência irregular, o que propicia um sentimento de não pertencimento e desmotivação com o ambiente escolar, ou ainda, com os conteúdos que estão sendo trabalhados ocasionando elevado índice de retenção no Ensino Médio.

Nesse mundo globalizado em que os jovens estão sendo atraídos pelo uso das tecnologias, redes sociais e, nas quais todas as informações são muito rápidas e isoladas, não estão sendo atraídos para a sistemática de um aprendizado das dinâmicas aplicadas em sala de aula, contribuindo para um convívio social restrito o que remete a individualidade nas ações, nas atitudes e falta de valores tanto morais quanto sociais.

Em nossa Unidade Escolar, temos o privilégio de ter espaços que nos oportunizam uma adequação na tentativa de transformar as dinâmicas e as metodologias de sala de aula. Após discussão em reuniões de Conselho de Escola, que envolveu pais, alunos, professores, funcionários e gestores concluíram que necessário se faz a revitalização do espaço externo da escola, pois os outros já existentes, que são: Sala de Leitura, Sala de Informática e as quadras tanto interna quanto a externa estão apropriadas para a diversidade. 
Possuímos uma mesa de alvenaria com cobertura, da qual chamamos de "mesão", localizada no entorno da quadra de vôlei, que permite uma interação e um convívio social saudável. É um espaço em que os alunos apreciam e se sentem mais livres.

A intenção é: associar o sentimento de liberdade da juventude com o ambiente pedagógico.

Foi elaborado um croqui para esta revitalização no qual além da reforma do "mesão" serão construídas 4 mesas de alvenaria com bancos fixos para 4 lugares e 2 mesas com 6 lugares, sendo que o revestimento das mesas de 4 lugares serão delineadas para jogo de xadrez.

Espaço este que deverá ser utilizado pelos professores em suas aulas com metodologias diferenciadas para abranger a diversidade cognitiva, seduzindo o aluno a envolver-se em seu processo de aprendizagem, consequentemente garantirá sua frequência e permanência no ambiente escolar.

Projetos a serem desenvolvidos neste espaço cultural:

XadreZ

Objetivo:Desenvolver e acelerar o raciocínio lógico.

Leitura

Objetivo: Perceber que toda leitura pode e deve ser prazerosa.

Nivelamento

Objetivo: Agrupar conforme dificuldade/necessidade nas habilidades e competências contemplando todas as áreas de conhecimento.

Teatro

Objetivo: Espaço para estudar e ensaiar as cenas dos títulos estudados. Foco para dicção, uso da oralidade e memorização.

Concluindo, uma gestão democrática de qualidade, apoiada em um colegiado participativo e dinâmico, trabalhando com Coordenador que tenha uma visão circular reflete diretamente na qualidade da educação, pois tais atitudes de liderança interferem diretamente na sala de aula, sendo estas projetadas nos índices dos resultados das avaliações externas, sendo elas: Prova Brasil que gera o Índice de Desenvolvimento da Educação Básica, IDEB e do Saresp, que envolve o resultado do desempenho da sala de aula e o fluxo da escola e este gera o Índice de Desenvolvimento do Estado de São Paulo - IDESP.

\section{Caracterização do produto/serviço e/ou processo}

A institucionalização de um ambiente na escola como local acolhedor, prazeroso e diferenciado, no qual o aluno, de acordo com os princípios e premissas do modelo pedagógico do Programa Ensino Integral que pressupõe a escola alinhada com a realidade do jovem, preparando-o para realizar seu projeto de vida e ser protagonista de sua formação, tenha oportunidades e momentos diferenciados de convivência e aprendizado através da revitalização do ambiente externo já existente na escola, composto por uma mesa de grande porte de alvenaria com cobertura e a construção de seis mesas com bancos fixos de porte menor distribuída pela área, que proporcionará a diversificação nas ações de aprendizagem e de protagonismo juvenil.

O espaço terá como um diferencial a sua utilização de forma democrática, na qual toda comunidade escolar poderá fazer uso, tanto nas ações voltadas ao protagonismo juvenil, quanto no que tange a atividades de cunho especificamente pedagógicos que serão alinhavadas pelos professores das diversas disciplinas nas áreas de conhecimento do currículo e da parte diversificada, através de projetos que tenham como foco central o maior envolvimento dos alunos do ensino médio, objetivando atingir diretamente o indicador de fluxo projetado pela escola no IDESP, garantindo sua frequência e permanência no ambiente escolar e consequentemente a melhoria em seu rendimento acadêmico. 
Este empreendimento foi inspirado no projeto da Escola Estadual Uacury Ribeiro de Assis Bastos, localizada em Campinas à Rua Maria Salome Bras, 80 - Jardim Monte Belo, que busca parceiros para desenvolvê-lo e tem como meta disponibilizar um ambiente cultural diferenciado, prazeroso, onde possam participar de aulas diferenciadas e participativas, conforme ilustrações a seguir.
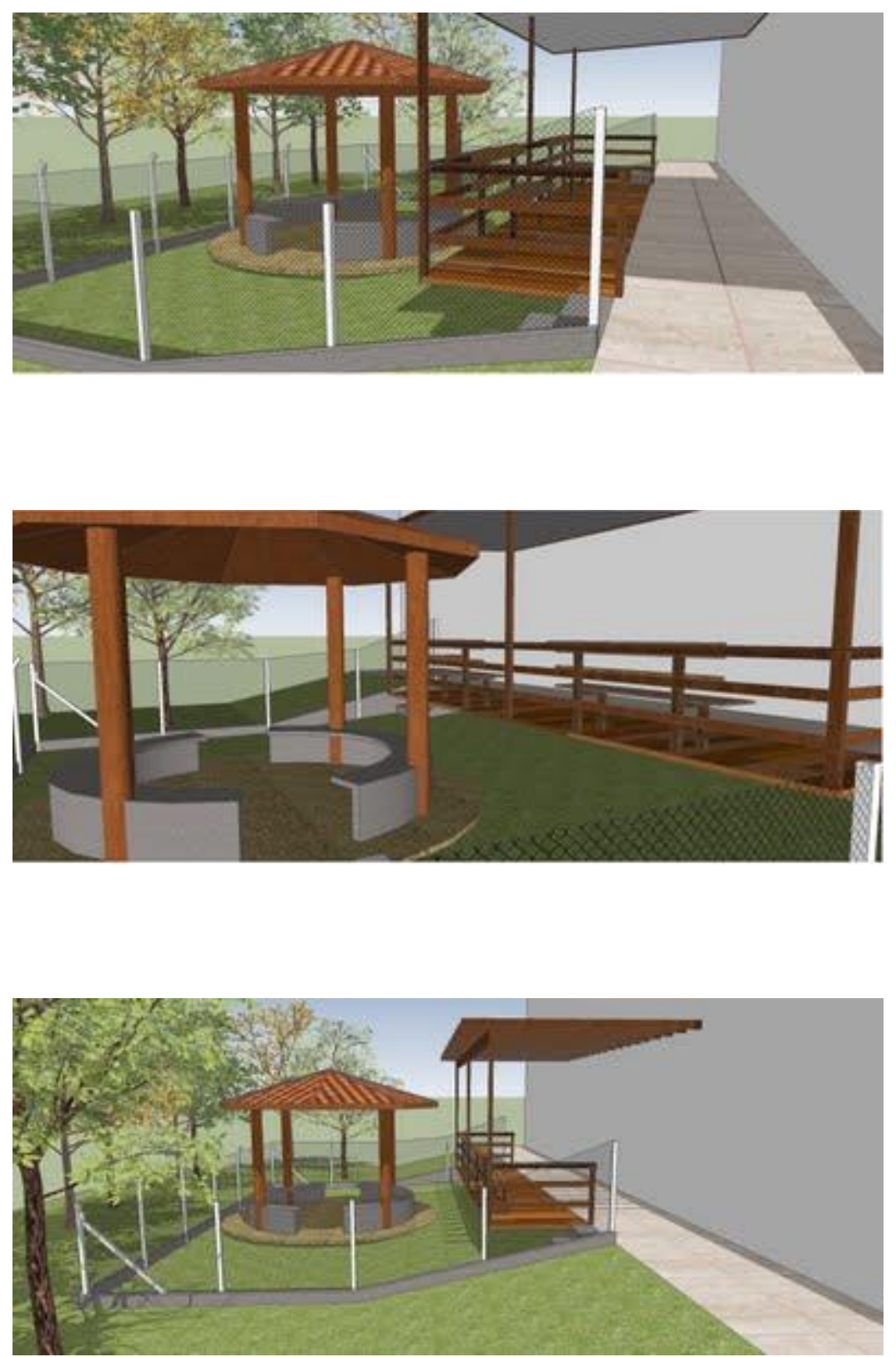

A continuidade das ações compreende na conservação e manutenção do aparelho, a fomentação das ações do protagonismo juvenil tendo o espaço também como estímulo. Criar a cultura da utilização da área na realização dos mais variados projetos.

\section{Estratégia de implementação}

Com a finalidade de visualizar e facilitar as escolhas para as estratégias de implementação deste projeto utilizaremos a análise SWOT/FOFA (força/oportunidade - fraqueza/ameaça), conforme segue: 


\section{Diagnóstico interno:}

\section{FORÇAS}

- A aceitabilidade da comunidade escolar;

- Novidade para os alunos do Ensino Médio;

- Institucionalização do ambiente.

\section{FRAQUEZAS}

- Espaço não ser agradável;

- Espaço não revitalizado;

- A não obtenção de recursos suficientes para a execução do projeto.

\section{Diagnóstico externo:}

\section{OPORTUNIDADES}

- Inserção da escola no Proemi (Programa Ensino Médio Inovador);

- Autonomia de escolha na utilização do recurso;

- Programa Ensino Integral oferece oportunidades de participar de programas de melhorias para 0 Ensino Médio.

\section{AMEAÇAS}

- Não aprovação do projeto de revitalização por parte dos órgãos superiores, o que inviabilizaria todas as ações;

- Recursos já pré-destinados, sem autonomia de escolha em sua aplicabilidade;

- A morosidade no recebimento dos recursos por consequência dos trâmites burocráticos;

\begin{tabular}{c|c|c}
\hline \multicolumn{2}{|c}{ Definição das estratégias } \\
\hline Objetivos & Metas & \multicolumn{1}{c}{ Estratégias } \\
\hline $\begin{array}{c}\text { Melhoria dos índices da } \\
\text { escola nas avaliações } \\
\text { externas }\end{array}$ & $\begin{array}{c}\text { Aumento de 6\% no IDESP em } \\
\text { relação ao índice de 2013 }\end{array}$ & $\begin{array}{c}\text { Desenvolver projetos voltados a leitura e escrita, } \\
\text { utilizando o ambiente revitalizado }\end{array}$ \\
\hline $\begin{array}{c}\text { Redução da taxa de } \\
\text { retenção/evasão no } \\
\text { Ensino Médio }\end{array}$ & $\begin{array}{c}\text { Reduzir em 80\% a quantidade } \\
\text { de alunos retidos e em 100\% a } \\
\text { evasão, para 2015 }\end{array}$ & $\begin{array}{l}\text { Estimular o interesse dos alunos pelo ambiente } \\
\text { escolar; } \\
\text { Desenvolver atividades extracurriculares que } \\
\text { reforcem a relação do aluno com a escola. }\end{array}$ \\
\hline
\end{tabular}




\begin{tabular}{c|c|l}
\hline $\begin{array}{c}\text { Espaço diferenciado de } \\
\text { aprendizagem }\end{array}$ & $\begin{array}{c}100 \% \text { de utilização e } \\
\text { aceitabilidade do ambiente }\end{array}$ & $\begin{array}{l}\text { Revitalizar e adaptar o espaço externo da escola; } \\
\text { Otimizar a execução de atividades que utilizem o } \\
\text { espaço como variante das ações pedagógicas de } \\
\text { todas as áreas de conhecimeno. }\end{array}$ \\
\hline Ações do protagonismo & $\begin{array}{c}50 \% \text { de alunos desenvolvendo } \\
\text { juções do Clube Juvenil no } \\
\text { ambiente }\end{array}$ & $\begin{array}{l}\text { (instituição prevista no Programa Ensino Integral) a } \\
\text { utilização do local com atividades por eles } \\
\text { organizadas. }\end{array}$ \\
\hline
\end{tabular}

Utilizando o modelo 5W2H focando o projeto Revitalização de Espaços Culturais/ Pedagógicos, podemos definir as principais ações conforme segue:

\begin{tabular}{|l|l|}
\hline \multicolumn{2}{|c|}{ PLANO DE AÇÃo } \\
\hline O quê? & $\begin{array}{l}\text { 1.Revitalizar o ambiente externo existente na escola } \\
\text { 2.Desenvolvimento de projetos } \\
\text { 3.Ações Protagonistas }\end{array}$ \\
\hline Quem? & $\begin{array}{l}\text { 1.APM - Associação de Pais e Mestres } \\
\text { 2.Professores do Ensino Médio } \\
\text { 3.Alunos }\end{array}$ \\
\hline Onde? & $\begin{array}{l}\text { 1.Escola } \\
\text { 2.No espaço revitalizado } \\
\text { 3.No espaço revitalizado }\end{array}$ \\
\hline Quando? & $\begin{array}{l}\text { 1.2014 } \\
\text { 2.2014/2015 } \\
\text { 3.2015 }\end{array}$ \\
\hline Por quê? & $\begin{array}{l}\text { 1.Atingir índice de fluxo mais próximo a 1, apontado no IDESP } \\
\text { 2.Aumento do IDESP } \\
\text { 3.Fomentar ações protagonistas }\end{array}$ \\
\hline Como? & $\begin{array}{l}\text { 1.Recursos provenientes da verba federal para o PROEMI - Programa Ensino } \\
\text { Médio Inovador } \\
\text { 2.Planejamento, execução e avaliação dos projetos elaborados } \\
\text { 3. Planejamento, execução e avaliação dos projetos elaborados } \\
\text { R\$ 11.120,00 }\end{array}$ \\
\hline
\end{tabular}


Os indicadores para acompanhamento do projeto serão:

- Índice de aceitação e satisfação dos alunos;

- Gradual aumento nos resultados das avaliações, internas/externas;

- Indicador de Fluxo igual a 1. (O indicador de fluxo (IF) é uma medida sintética da promoção dos alunos e varia entre zero e um que é utilizada no cálculo do IDESP).

Recursos necessários para a implementação do Projeto :

\begin{tabular}{|c|c|c|}
\hline \multicolumn{3}{|c|}{ Recursos necessários } \\
\hline O que vou precisar & Descrição & Como obter \\
\hline Materiais para reparos & $\begin{array}{l}\text { Substituição do piso existente no área } \\
\text { coberta; } \\
\text { Reparo no telhado e estrutura metálica. }\end{array}$ & $\begin{array}{l}\text { Elaboração do projeto e } \\
\text { encaminhamento ao MEC/FNDE para } \\
\text { aprovação e liberação da verba para } \\
\text { sua execução. }\end{array}$ \\
\hline Materias para pintura & Pintura da estrutura metálica e geral & $\begin{array}{l}\text { Elaboração do projeto e } \\
\text { encaminhamento ao MEC/FNDE para } \\
\text { aprovação e liberação da verba para } \\
\text { sua execução. }\end{array}$ \\
\hline $\begin{array}{c}\text { Confecção das mesas e } \\
\text { bancos }\end{array}$ & Trabalho de alvenaria & $\begin{array}{l}\text { Elaboração do projeto e } \\
\text { encaminhamento ao MEC/FNDE para } \\
\text { aprovação e liberação da verba para } \\
\text { sua execução. }\end{array}$ \\
\hline Acabamentos & $\begin{array}{l}\text { Revestimento da mesa existente e nas } \\
\text { que serão construídas revestimento tipo } \\
\text { tabuleiro de xadrez }\end{array}$ & $\begin{array}{l}\text { Elaboração do projeto e } \\
\text { encaminhamento ao MEC/FNDE para } \\
\text { aprovação e liberação da verba para } \\
\text { sua execução. }\end{array}$ \\
\hline Professores & $\begin{array}{c}\text { Desenvolvimento de projetos das } \\
\text { disciplinas da parte diversificada e } \\
\text { currículo }\end{array}$ & Sem necessidade de recursos extras \\
\hline Alunos & Ações Protagonistas & Sem necessidade de recursos extras \\
\hline
\end{tabular}




\section{Marketing e comunicação}

A adesão ao modelo pedagógico do Programa Ensino Integral para este ano letivo, por esta unidade escolar, proporcionou a possibilidade da elaboração do projeto disponibilizado e oportunizado pelo programa PROEMI - Programa Ensino Médio Inovador - MEC/FNDE em revitalizar espaços culturais/pedagógicos com aclamação unanime dos pais na reunião pertinente ao assunto abordado.

Um ambiente adaptado propício para atender as especificidades do projeto, sendo explanado/divulgado pelos professores a todos os alunos de como, quando e por quem será utilizado estrategicamente no desenvolvimento dos variados projetos, e na mesma amplitude as ações protagonistas que poderão estar sendo desenvolvidas no local revitalizado.

Para que o projeto alcance êxito todo o processo será registrado e divulgado nos murais da escola através de cartazes com fotos de todas as fases em andamento.

Outro meio de divulgação será através do blog que está sendo construído pelos alunos na disciplina eletiva, "BLOG EM AÇÃO". Esta disciplina é um dos componentes da Parte Diversificada e, deve promover o enriquecimento, a ampliação e a diversificação de conteúdos, temas ou áreas do Núcleo Comum. Considera a interdisciplinaridade enquanto eixo metodológico para buscar a relação entre os temas explorados, respeitando as especificidades das distintas áreas de conhecimento.

As reuniões de pais também serão usadas como estratégia de divulgação na qual será proporcionada a visita do ambiente para os presentes.

Apostamos que, o aluno gostando e respeitando o ambiente, o mesmo será o multiplicador dos benefícios da utilização deste espaço e automaticamente preservará o lugar.

\section{Organização e gerência do empreendimento}

\section{Perfil e Experiência da Equipe Gestora}

\begin{tabular}{|c|c|c|c|}
\hline NOME & FUNÇÃO & $\begin{array}{l}\text { FORMAÇÃO E } \\
\text { EXPERIÊNCIA }\end{array}$ & $\begin{array}{c}\text { PRINCIPAIS ATIVIDADES } \\
\text { (NO PROJETO) }\end{array}$ \\
\hline Nemésio Boni & Diretor de Escola (D) & $\begin{array}{l}\text { Formado em Educação Física, } \\
\text { cursando atualmente MBA } \\
\text { Gestão Empreendedora em } \\
\text { Educação. Regente de turmas } \\
\text { desde } 1991 \text { e nesta escola na } \\
\text { função de gestor desde } 2007 \text {. }\end{array}$ & $\begin{array}{l}\text { Gestor responsável pela tomada } \\
\text { de preços, orçamentos } \\
\text { solicitando deliberação em } \\
\text { reunião com a APM e prestação } \\
\text { de contas das verbas destinadas } \\
\text { à escola. } \\
\begin{array}{l}\text { Contratar responsáveis pela } \\
\text { obra/reparos. }\end{array}\end{array}$ \\
\hline
\end{tabular}




\begin{tabular}{|c|c|c|c|}
\hline Maria Bellezoni Marinho & $\begin{array}{l}\text { Vice-Diretora de Escola } \\
\text { (VD) }\end{array}$ & $\begin{array}{l}\text { Formada em Matemática, pós } \\
\text { graduada em Gestão da Escola } \\
\text { pela USP em 2011, cursando } \\
\text { atualmente MBA Gestão } \\
\text { Empreendedora em Educação. } \\
\text { Regente de turma desde 1991, } \\
\text { e nesta escola na função de } \\
\text { Vice-Diretor desde 2007. }\end{array}$ & $\begin{array}{l}\text { Planejar as ações destinadas à } \\
\text { utilização dos espaços } \\
\text { culturais/pedagógicos. } \\
\text { Marcar as reuniões de divulgação } \\
\text { do projeto junto aos professores } \\
\text { e pais. }\end{array}$ \\
\hline $\begin{array}{ll}\text { Alessandra } & \text { Barbosa } \\
\text { Escobar Arange } & \end{array}$ & $\begin{array}{l}\text { Professor Coordenador } \\
\text { Geral (PCG) }\end{array}$ & $\begin{array}{l}\text { Formada em Ciências Físicas e } \\
\text { Biológicas, pós graduada em } \\
\text { Gestão do Currículo pela USP } \\
\text { em 2011, professora de } \\
\text { Ciências desde 2003, e nesta } \\
\text { escola atua na função de } \\
\text { coordenadora geral. }\end{array}$ & $\begin{array}{l}\text { Executar e controlar o projeto. } \\
\text { Organizar a agenda de utilização } \\
\text { dos } \\
\text { culturais/pedagógicos. }\end{array}$ \\
\hline
\end{tabular}

\section{Principais processos}

A tabela a seguir, mostra o perfil da equipe e os principais processos de trabalho necessários para a realização do empreendimento:

\begin{tabular}{||c|c|c||}
\hline $\begin{array}{c}\text { PROCESSOS DO } \\
\text { EMPREENDIMENTO }\end{array}$ & COLABORADOR & PERFIL NECESSÁRIO \\
\hline \hline $\begin{array}{c}\text { Confeccionar materiais para as } \\
\text { reuniões de divulgação do } \\
\text { projeto, junto à APM. }\end{array}$ & Nemésio Boni & $\begin{array}{l}\text { Bom relacionamento e boa } \\
\text { comunicação verbal. } \\
\text { Reconhecimento da comunidade } \\
\text { pelos trabalhos e projetos que } \\
\text { desenvolve na Escola. }\end{array}$ \\
\hline $\begin{array}{c}\text { Coordenação e acompanhamento } \\
\text { da compra dos materiais e } \\
\text { contratação de prestador de } \\
\text { serviços. }\end{array}$ & Nemésio Boni & Administrador com amplo leque \\
\hline
\end{tabular}




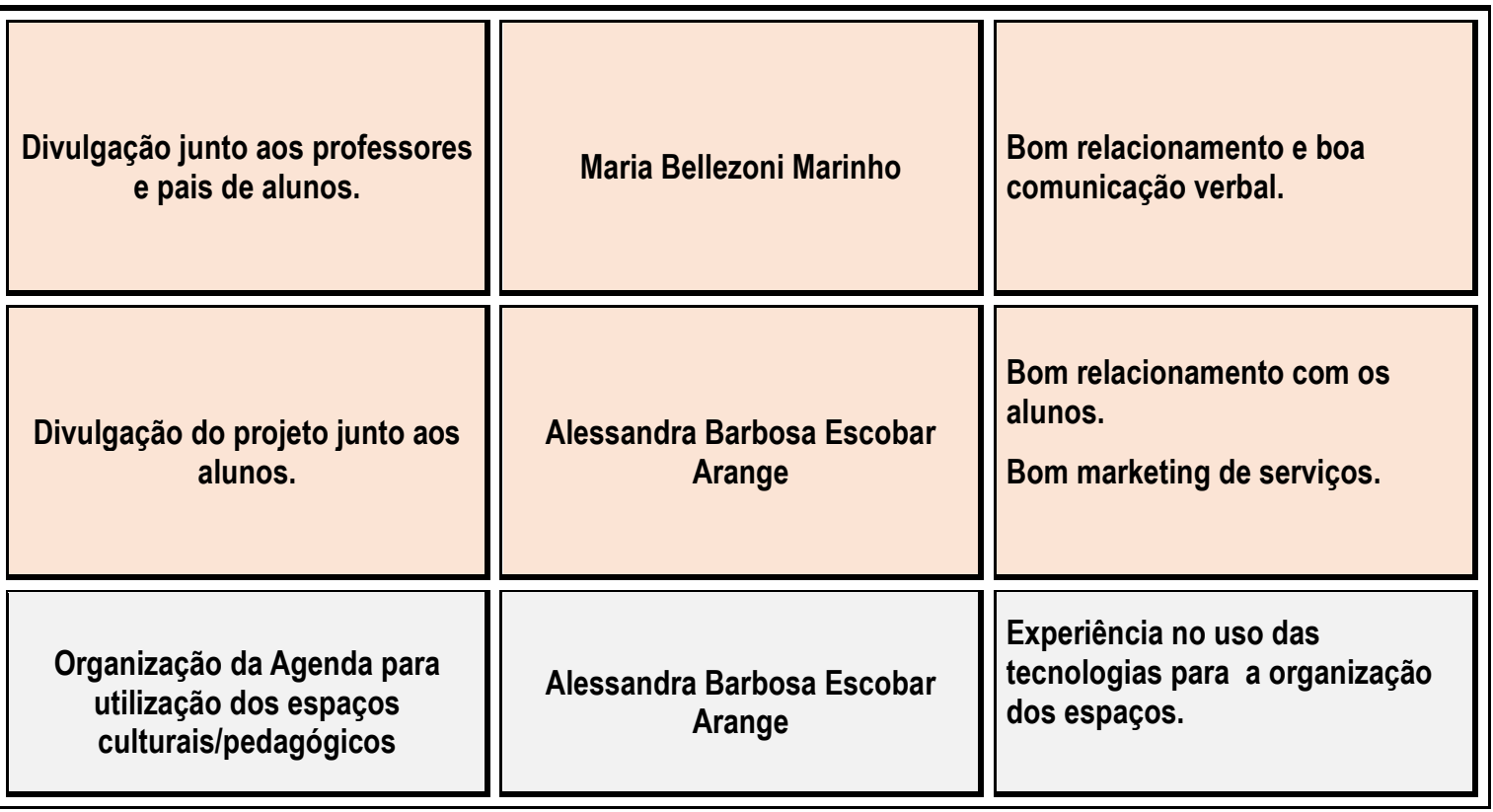

\section{Plano financeiro}

\section{Investimento (despesa de capital)}

\begin{tabular}{|c|c|c|c|}
\hline \multicolumn{4}{|c|}{ Investimentos (despesas de capital) } \\
\hline \multicolumn{1}{|c|}{ Item } & Ano1 & An02 & Ano3 \\
\hline Obras e infraestrutura & $1.850,00$ & $\mathbf{0 , 0 0}$ & $\mathbf{0 , 0 0}$ \\
\hline Substituição do piso da área coberta & $1.200,00$ & $\mathbf{0 , 0 0}$ & $\mathbf{0 , 0 0}$ \\
\hline $\begin{array}{l}\text { Reparo no telhado e estrutura } \\
\text { metálica }\end{array}$ & 650,00 & $\mathbf{0 , 0 0}$ & $\mathbf{0 , 0 0}$ \\
\hline Material & $4.020,00$ & & $\mathbf{0 , 0 0}$ \\
\hline Material de construção & $2.500,00$ & $\mathbf{0 , 0 0}$ & $\mathbf{0 , 0 0}$ \\
\hline Material de pintura & $1.520,00$ & $\mathbf{0 , 0 0}$ & $\mathbf{0 , 0 0}$ \\
\hline Total & $5.870,00$ & & \\
\hline
\end{tabular}

\section{Detalhamento:}

- Areia

- Pedra

- Cimento

- Cal

- Argamassa

- Rejunte

- Cerâmica

- Tinta

- Ferragem

- Pastilha de vidro

- Massa corrida

- Pintura do ambiente

- Construção das mesas em alvenaria. 
Revitalização de espaços culturais/pedagógicos

- Despesas correntes

\begin{tabular}{|c|c|c|c|}
\hline \multicolumn{4}{|c|}{ Projeção das Despesa Correntes } \\
\hline Serviços de Terceiros & Total Ano 1 & Total Ano 2 & Total Ano 3 \\
\hline Pedreiro & $3.800,00$ & 0,00 & 0,00 \\
\hline Pintor & $1.450,00$ & 0,00 & 0,00 \\
\hline Total de Despesas & $5.250,00$ & 0,00 & 0,00 \\
\hline
\end{tabular}

Detalhamento:

- Contratação de mão de obra especializada em construção e pintura.

Despesas Administrativas e de Pessoal

\begin{tabular}{|c|c|c|c|c|}
\hline \multicolumn{5}{|c|}{ Projeção das Despesa Administrativas e de Pessoal } \\
\hline Administrativas & setembro & outubro & novembro & dezembro \\
\hline Energia Elétrica & 40,00 & 40,00 & 40,00 & 40,00 \\
\hline Marketing & 15,00 & 15,00 & 15,00 & 15,00 \\
\hline Total & 55,00 & 55,00 & 55,00 & 55,00 \\
\hline Pessoal & & & & 800,00 \\
\hline Professores & 800,00 & 800,00 & 800,00 & $16.328,44$ \\
\hline Gestores & $16.328,44$ & $16.328,44$ & $16.328,44$ & $17.128,44$ \\
\hline Total & $17.128,44$ & $17.128,44$ & $17.128,44$ & $17.183,44$ \\
\hline $\begin{array}{l}\text { Total das Despesas } \\
\text { Adm./Pess. }\end{array}$ & $17.183,44$ & $17.183,44$ & $17.183,44$ & \\
\hline
\end{tabular}

Detalhamento:

- 10 professores - 02 horas/aula por semana a $\mathrm{R} \$ 10,00$

- 03 gestores - $\mathbf{4 0}$ horas semanais.

Necessidade de recursos

\begin{tabular}{|l|c|c|c|c|}
\hline \multicolumn{4}{|c|}{ Cálculo da Necessidade de Recursos } & \\
\hline \multicolumn{1}{|c|}{ Item } & ANO 1 & ANO 2 & ANO 3 & TOTAL \\
\hline I. Total das Despesas Correntes & $\mathbf{5 . 2 5 0 , 0 0}$ & $\mathbf{0 , 0 0}$ & $\mathbf{0 , 0 0}$ & $\mathbf{5 . 2 5 0 , 0 0}$ \\
\hline Material de Consumo & 0,00 & 0,00 & 0,00 & 0,00 \\
\hline Passagens e Despesas com Locomoção & 0,00 & 0,00 & 0,00 & 0,00 \\
\hline Serviços de Terceiros & $5.250,00$ & 0,00 & 0,00 & $5.250,00$ \\
\hline II. Total de Despesas Administrativas & $\mathbf{2 2 0 , 0 0}$ & $\mathbf{0 , 0 0}$ & $\mathbf{0 , 0 0}$ & $\mathbf{2 2 0 , 0 0}$ \\
\hline III. Total de Despesas com Pessoal & $\mathbf{6 8 . 5 1 3 , 7 6}$ & $\mathbf{0 . 0 0}$ & $\mathbf{0 , 0 0}$ & $\mathbf{6 8 . 5 1 3 , 7 6}$ \\
\hline IV. Total de Despesas de Capital (investimentos) & $\mathbf{5 . 8 7 0 , 0 0}$ & $\mathbf{0 , 0 0}$ & $\mathbf{0 , 0 0}$ & $\mathbf{5 . 8 7 0 , 0 0}$ \\
\hline Necessidade de Recursos (I+II+III+IV) & $\mathbf{7 9 . 8 5 3 , 7 6}$ & $\mathbf{0 , 0 0}$ & $\mathbf{0 , 0 0}$ & $\mathbf{7 9 . 8 5 3 , 7 6}$ \\
\hline Recursos Edital & $11.120,00$ & 0,00 & 0,00 & $11.120,00$ \\
\hline Recursos da Organização (contrapartida) & $68.733,76$ & 0,00 & 0,00 & $\mathbf{6 8 . 7 3 3 , 7 6}$ \\
\hline
\end{tabular}

